\title{
Project-based learning of advanced CAD/CAE tools in engineering education
}

\author{
Giovanni Berselli ${ }^{1}\left[\right.$ P $\cdot$ Pietro Bilancia ${ }^{1} \cdot$ Luca Luzi $^{2}$
}

Received: 6 April 2020 / Accepted: 27 July 2020 / Published online: 14 August 2020

(C) The Author(s) 2020

\begin{abstract}
The use of integrated Computer Aided Design/Engineering (CAD/CAE) software capable of analyzing mechanical devices in a single parametric environment is becoming an industrial standard. Potential advantages over traditional enduring multi-software design routines can be outlined into time/cost reduction and easier modeling procedures. To meet industrial requirements, the engineering education is constantly revising the courses programs to include the training of modern advanced virtual prototyping technologies. Within this scenario, the present work describes the CAD/CAE project-based learning (PjBL) activity developed at the University of Genova as a part of course named Design of Automatic Machines, taught at the second level degree in mechanical engineering. The PjBL activity provides a detailed overview of an integrated design environment (i.e. PTC Creo). The students, divided into small work groups, interactively gain experience with the tool via the solution of an industrial design problem, provided by an engineer from industry. The considered case study consists of an automatic pushing device implemented in a commercial machine. Starting from a sub-optimal solution, the students, supervised by the lecturers, solve a series of sequential design steps involving both motion and structural analysis. The paper describes each design phase and summarizes the numerical outputs. At last, the results of the PjBL activity are presented and commented by considering the opinions of all the parties involved.
\end{abstract}

Keywords Virtual modeling · Integrated CAD/CAE design · Project-based learning · Engineering education · Interactive education

\section{Introduction}

In the last decades, the development of efficient ComputerAided Design (CAD) and Computer-Aided Engineering (CAE) tools have enabled important changes in the engineering world [1]. CAD is currently widely used from industries, academies and freelance designers for developing new products, layouts or processes [2]. The fully parametric representation of the objects allows to refine the ideas

Giovanni Berselli

giovanni.berselli@unige.it

Pietro Bilancia

pietro.bilancia@edu.unige.it

Luca Luzi

luca.luzi3@unibo.it

1 Department of Mechanical, Energy, Management and Transportation Engineering, University of Genova, Genova, Italy

2 Department of Industrial Engineering, University of Bologna, Bologna, Italy before implementing a manufacturing process, limiting the source of errors as well as the expenses. In parallel, CAE technologies are exploited for accurate behavioral modeling and support the engineers throughout the design process [3]. CAE simulations are useful, for example, to analyze the motion of components and assemblies (i.e. Multibody Analysis, MBD), to check deformation and stresses (i.e. Finite Element Analysis, FEA), to simulate the actuation system or to perform optimization studies. Compared to physical testing, virtual models have obvious advantages in terms of cost saving and capability to test the performance of several design variants in a limited time [3].

When approaching a design problem, an user-friendly platform comprising CAD and CAE tools that have the ability to co-operate is always desirable [4,5]. For instance, the structural optimization of industrial components combines a 3D parametric model with a pre-set FEA environment, capable of applying loads and constraints to the new geometry at each iteration of the process. Following the recent literature, such problem can be solved in two different ways: 
- by implementing multi-software frameworks comprising a set of specific CAD and CAE environments that have been conceived as stand-alone [6-10]. A clear advantage of this method is the possibility to include special purpose tools (e.g. ANSYS, Nastran, RecurDyn, Adams, etc.) in the framework and to exploit their potentialities to characterize the mechanical system with a high level of accuracy. As a drawback, connecting software that are not natively meant to work together may require extra time and expertise.

- by exploiting modern integrated CAD/CAE platforms (e.g. PTC Creo, Dassault system Catia and SolidWorks, Siemens NX and Solid Edge, Autodesk Inventor, etc.) $[5,11,12]$, namely multipurpose virtual prototyping technologies that allow to simulate mechanical and mechatronic systems, starting from the geometrical and parametric representation of parts. The recent releases incorporate MBD and FEA solvers, but also internal optimizers. Compared to the first strategy (i.e. the multisoftware approach), these packages may not satisfy high expectations when nonstandard boundary conditions as well as nonlinear analysis have to be pursued. However, the user can easily step from design to simulation without the need to deal with different software.

From a fast comparison, it is evident that the former approach is mostly exploited for research purpose, as the frameworks can be finely tailored to meet the design requirements/intents, whereas the latter is certainly suitable for industry, where easy-to-use and fast tools are still preferable. From a practical standpoint, these integrated CAD/CAE platforms allow to simulate the behavior of parts starting from the early-design stage, as schematized in Fig. 1, reducing the overall time-tomarket and product cost.

The gradual reduction of time between two consecutive new releases from the software vendors, and the introduction of sophisticated features (such as the topological optimization [13]) definitively prove the central role that these integrated CAD/CAE tools are assuming in the current industrial scenario. As a direct effect, the CAD/CAE training programs are gaining more and more importance to make it possible for engineers to operate successfully with these advanced computer technologies [14]. In particular, the engineering educational system must evolve following the industrial trends in order to give to young engineers the adequate level of expertise [15-17]. The CAD courses, typically divided between first and second level degrees, have been offered in mechanical engineering curricula for decades [18]. They primarily focus on teaching the fundamentals of technical drawing and on the practical use of the tool [19], i.e. the so-called command knowledge [20-22]. In particular, during the first level degree, the 2D CAD tools are proved to be effective for introducing the $2 \mathrm{D}$ drafting of simple
STANDARD APPROACH

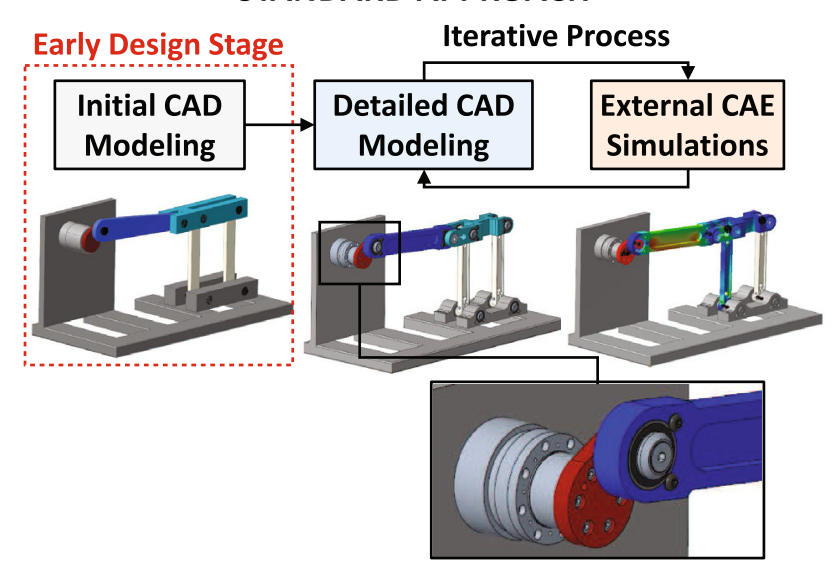

MODERN APPROACH

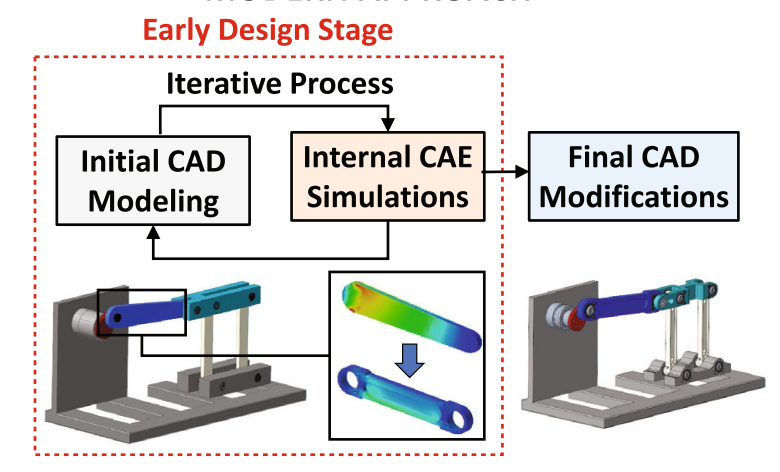

Fig. 1 Standard versus modern industrial design approach

mechanical parts and schemes, for explaining the technical drawing symbols, notations and standards, but also basic mechanism kinematics and statics principles[23-25]. Then, medium/advanced courses typically introduce the $3 \mathrm{D}$ parametric CAD tools. Concerning the CAE courses, these are commonly given in the second level degree, i.e. when the students have developed solid basis in machine analysis/design theories. The behavioral modeling of mechanical and mechatronic systems is considered a part of procedural knowledge [26], since it trains the ability of the students in solving practical engineering problems by selecting the most convenient approach. The CAD part is usually kept as a separate entity in traditional CAE classes. The CAD model is generated and then transferred to the CAE software with neutral file formats, such as step STEP or IGES [27]. This approach surely helps the lecturers in getting the students attentions on the analysis settings (boundary conditions, materials selection and properties, algorithms, etc.) and the subsequent results post-processing techniques. As a direct effect, the students develop a vast knowledge of dedicated CAE tools, which plays a key role in their future career.

Following the above-mentioned industrial trends, aiming at reducing the gap between design and simulation environments, courses that teach integrated $\mathrm{CAD} / \mathrm{CAE}$ programs 
are now part of many engineering curricula $[28,29]$ (often as optional subjects), or as part of postgraduate programs. They are focused on a single CAD/CAE package, chosen in line with specific factors, such as design capabilities of the software package, quality of results, use in industry or research, licence cost and learning difficulty $[29,30]$. Recent researches considered also the possibility to employ open-source CAD/CAE software [31], though these packages (e.g. FreeCAD and OpenSCAD) have not yet reached a sufficient level to become valuable substitutes for commercial ones [32].

Building upon these introductory considerations, this paper reports a detailed overview of the Project-Based Learning (PjBL) activity [33-35] carried out at the University of Genova within the course named "Design of Automatic Machines", as a part of the second level degree in mechanical engineering. The recent literature in the field of engineering education shows a growing interest in the use of $\mathrm{PjBL}$ as an active learning approach [36,37] that emphasizes the project and stimulates collaboration and teamwork. Demonstrative examples are reported in [35,38-46]. Practically speaking, PjBL may be interpreted as an assignment that the students have to complete by leveraging their theoretical background and by performing constructive investigations. It can be considered as an effective method for tying together several subjects. The possibility to deal with real problems shows positive results and feedback from students [40].

The proposed course is equally divided into theoretical lessons and CAD/CAE exercises, that are taught with the $\mathrm{PjBL}$ approach. In line with the study reported in [47], the practical part starts with a seminar given by a welltrained engineer from industry, whose role is to present a design problem related to the world of automatic machines. The mechanical system under investigation is a purposely selected subgroup, namely a planar device extrapolated from an industrial automatic machine. After a comprehensive discussion about the system functional principles and issues, the seminar ends with the assignment of a specific set of tasks, which basically replicate the design steps performed by the experienced industrial engineers, from the initial (sub-optimal) configuration to the final prototype [48]. The students are asked to solve the proposed issues, by using a single CAD/CAE software, under the supervision of the lecturers. Among the commercial CAD/CAE software, PTC Creo has been selected mainly for two reasons: i) the licence availability in the university laboratories; ii) it covers all the stages of a CAD/CAE process, from the initial CAD design to more advanced CAE simulations (MBD and FEA).

As suggested in [49] and further discussed in [35], the students are divided in groups of 2-4 people. Larger groups would obviously require more internal organization, with the concrete risk that some members carry the most of the workload. On the contrary, smaller groups will not promote the co-operation between members, that is a central characteristic of PjBL. At the end of the PjBL activity the students have potentially incremented their problem solving abilities, along with their CAD/CAE skills. Only at this stage, each group proposes a novel design improvement and writes a detailed report about the project activity. All the CAD/CAE design steps are critically discussed in an interactive oral presentation, which constitutes the $50 \%$ of the final score. The remaining part of the exam includes a written and oral test, based on the theoretical topics presented during the course. In summary, the educational goals of the PjBL activity may be summarized as follows:

- to develop strategic knowledge [50], i.e. to train the capability of analyzing and solving an engineering problem under a concurrent set of design constraints, and to stimulate the interactive and critical review of the results;

- to achieve advanced specific skills in the use of industrially relevant integrated $\mathrm{CAD} / \mathrm{CAE}$ tools, namely (i) parametric $\mathrm{CAD}$, (ii) motion analysis with MBD solver, (iii) FEA verification of parts, (iv) internal optimization routines for design improvements;

- to encourage students to interactively work in a group (and not individually), i.e. to participate in their own learning process and to present the results of the work (via written report and oral exposition);

- to stimulate students' creativity [51] in the solution of a design problem of real interest for industry. Within the problem solving activity, emphasis is put on the comparative evaluation of design variants, which are (in most cases) directly available thanks to system parametrization.

In the remaining part of the paper, the teaching methodology and the activity organization are described. A detailed explanation of the CAD/CAE design steps performed by the students is also provided. Then, the results of the teaching experience, both from students and lecturers point of view, are presented and discussed.

\section{An overview of the CAD/CAE project}

\subsection{The case study}

As previously introduced, the $\mathrm{PjBL}$ activity starts with a seminar, in which an engineer from industry presents a new design problem and provides the main specs and requirements of the automatic machine. To correctly modulate the students' workload over the course, which overall provides 6 credits (i.e. ECTS-European Credit Transfer System), equally divided between theoretical and practical parts, a 


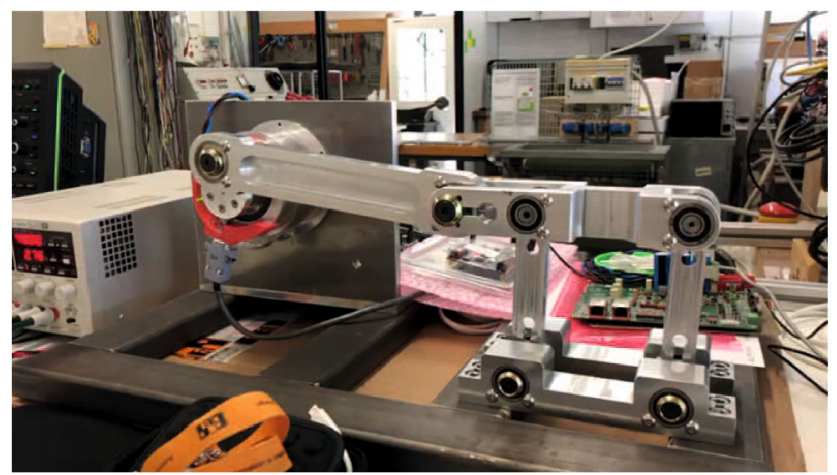

(a) APD lab physical prototype made in Aluminum alloy.

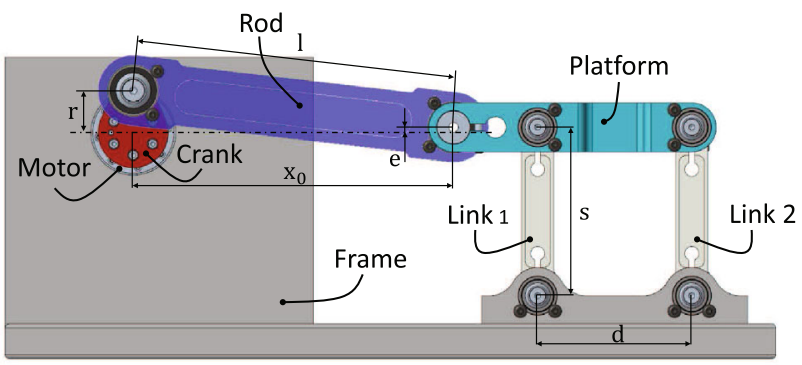

(b) CAD of the APD for PjBL.

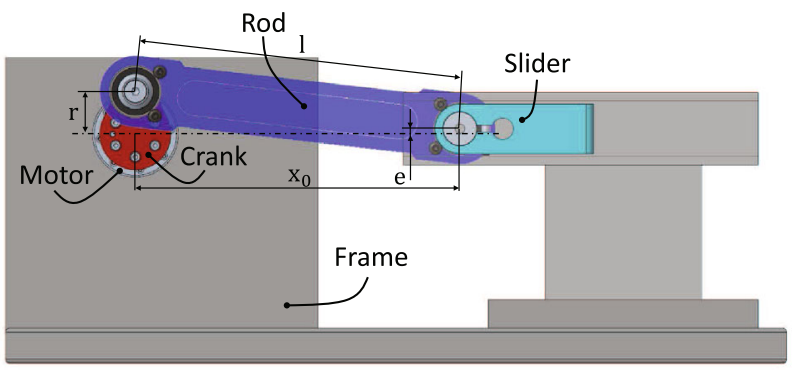

(c) Simplified CAD for teaching CAE simulations.

Fig. 2 The proposed case study for PjBL

Table 1 Initial APD dimensions and installation data

\begin{tabular}{lll}
\hline Symbol & Value & Unit \\
\hline$r$ & 30 & $\mathrm{~mm}$ \\
$l$ & 230 & $\mathrm{~mm}$ \\
$x_{0}$ & 228.5 & $\mathrm{~mm}$ \\
$d$ & 110 & $\mathrm{~mm}$ \\
$e$ & 3.8 & $\mathrm{~mm}$ \\
$s$ & 120 & $\mathrm{~mm}$ \\
\hline
\end{tabular}

single functional subgroup of the automatic machine is considered for the PjBL. The proposed subgroup is identified by a single Degree of Freedom (DoF) position-controlled linkage mechanism. Figure 2a, b report the last year assignment, namely a planar Automatic Pushing Device (APD), composed of a slider-crank linkage and a parallel four-bar linkage. The initial dimensions of each component (Crank, Rod, Link 1,2) are given during the seminar and are summarized in Table 1.
Such device topology turned out to be particularly convenient for the aim of the course, essentially for three main reasons: (i) as a 1 DoF system (see Fig. 2a, b), the students are capable to easily predict the motion of each component, (ii) the $\mathrm{CAD} / \mathrm{CAE}$ design process is straightforward, making it possible for the students to gain both command and strategic knowledge without any complication, (iii) a simplified version of the system, represented by the well-known slidercrank linkage depicted in Fig. 2c, can be used by the lecturers for explaining the use of the CAD/CAE tool (i.e. PTC Creo).

\subsection{PjBL activity: sequential design approach}

Starting from the initial sub-optimal configuration realized in Aluminum alloy, the students will experience a sequential design process. With reference to the design flow in Fig. 3, the following CAD/CAE steps are approached, with around 4-h class time being allocated to each step:

- Step \#1 : CAD Modeling - The task is completed within the PTC Creo Assembly environment. Some parts (the ones involved in future CAE optimizations) have to be modeled, whereas the others are directly imported using neutral file formats. The APD assembly is created by assigning a set of kinematic joints.

- Step \#2 : Motion Analysis and Optimization - Once checked the proper functioning of the assembly in the virtual environment, this step explores the combined use of the MBD tool (i.e. Creo Mechanism) and the internal optimizer. A single objective optimization is performed with the aim of minimizing a pre-defined trajectory error on the platform (see Fig. 2b), namely a kinematic output requested by the user through the analysis measure tool.

- Step \#3 : Dynamic Analysis and Optimization - After assigning the material (Aluminum alloy) to all the components, the students perform a dynamic simulation to compute the required actuation torque for an assigned motion. An optimization is then run to minimize the actuation torque to the possible extent. Similarly to the previous step, the task is completed by integrating the MBD tool and the optimizer.

- Step \#4 : Structural Analysis and Optimization - The worst load case scenario is evaluated in the MBD environment by performing a dynamic simulation on the APD configuration resulting from the previous step. The loads are then automatically transferred from the MBD environment to the FEA environment (i.e. Creo Simulate) to perform static structural verification on components. A structural optimization study is then carried out on a single component (e.g. the rod) to minimize its overall mass. 


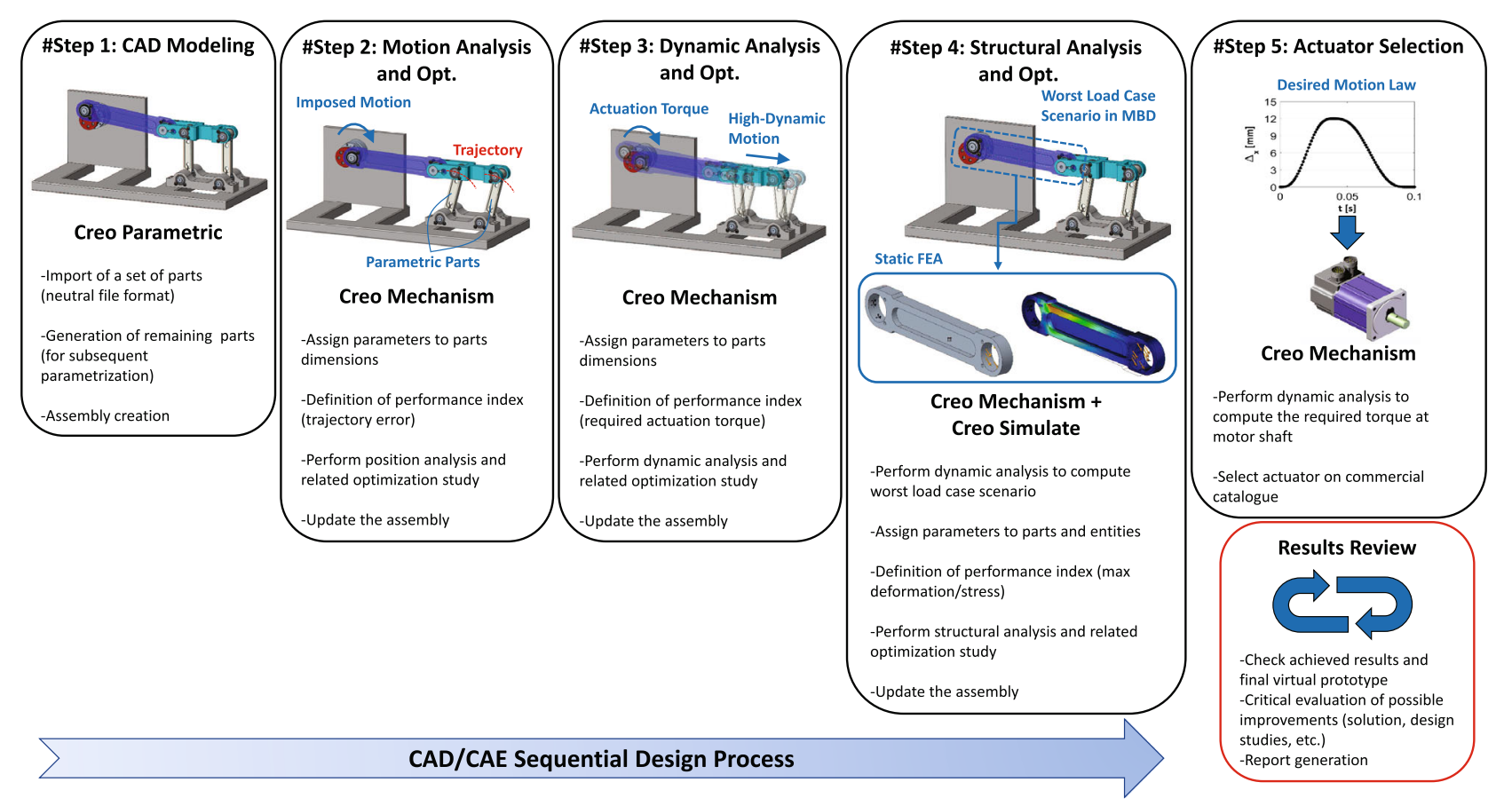

Fig. 3 Students design steps within the proposed PjBL activity

- Step \#5 : Actuator Selection - After the last geometry update, the motor selection is accomplished for the assigned motion law with a last dynamic simulation in the MBD environment, from which the characteristic torque-speed curve at the crank shaft is evaluated. Such numerical curve is then compared to the available motor characteristics (taken from the manufacturer's catalogs).

Naturally, the design process is not completely sequential and several iterations are always necessary due to the presence of critical aspects (e.g. unacceptable stress-strain condition evaluated in Step \#4, etc.), that could request the review of previous steps. In the next sections, the design methodology for each of these steps is described. At the end of the PjBL activity, the students revise the whole $\mathrm{CAD} / \mathrm{CAE}$ process with a critical approach before producing the final report.

\section{Virtual prototyping of the automatic pushing device}

\subsection{Step \# 1: CAD modeling}

Since the students involved in the course have already attended both introductory and medium CAD classes, which provide an in-depth training of the most used solid modeling features, the aim of this first design step is to teach the students the parametric modeling, i.e. the standard roles to be followed when designing parts that have to be subsequently investigated via CAE tools. Consequently, the initial APD configuration is made partially available for the students with neutral file formats. To take confidence with the parametric CAD environment, the students are expected to design the remaining parts (i.e. Rod and Link 1-2, see Fig. 2b). The exercise ends with the creation of the APD assembly, namely with the interconnection of parts through kinematic joints. The "Drag Component" tool is used to check the virtual model functioning. A regeneration option is then assigned to the model in order to set the APD's initial position, i.e. the one in which Link 1 and Link 2 are vertical.

\subsection{Step \#2: motion analysis and optimization}

The joints selection and application is an aspect of primary importance in view of the CAE analysis. Redundancies are excess constraints that do not apply any restrictions to the system motion, though they may lead to inaccurate results when performing dynamic analysis. Therefore, the presence of redundancies in the model is simply checked by running a kinematic analysis. The input motion can be a generic law (e.g. a constant velocity on the crank shaft), and the number of redundant constraints is made available by PTC Creo Mechanisms via the "Measure" tool. An example of overconstrained model is shown in Fig. 4a, which also represents the students' first version of the APD model. The updated model is shown in Fig.4b. 
In the following, a kinematic optimization study is conducted on the APD within the Step \#2, the input being a desired motion profile for the Platform (the APD's endeffector). With reference to Fig. 5, the dimension $s$, namely the length of Link 1,2, is adopted as parameter, whereas the Platform's trajectory error with respect to an ideal pure translational path, $\Delta_{y}$, is the cost function to be minimized. For an assigned motion profile, the problem can be expressed as follows:

$$
\begin{array}{rc}
\text { minimize } & e_{\text {tra }}=\max \left(\Delta_{y, i}\right) i=1, . ., n \\
\text { with respect to } & s \\
\text { subjected to } & s_{\min } \leq s \leq s_{\max }
\end{array}
$$

where $e_{\text {tra }}$ is the maximum error along the $y$-direction for the single simulation (run with $n$ steps), whereas $s_{\min }$ and $s_{\max }$ are the parameter's lower and upper bounds. While $s_{\min }$ can be simply assumed equal to $120 \mathrm{~mm}$ (i.e. the initial dimension, see Table 1), $s_{\max }$ has to be decided based on the available space within the automatic machine's compartment. This elementary optimization problem can be easily solved without the use of the CAD/CAE tool. In fact, with reference to Fig. $4 \mathrm{~b}$ and by defining $t$ as time, for an assigned motion along the $x$-direction, $\Delta_{x}=\Delta_{x}(t)$, the Link 1,2 rotation is simply obtained as $\alpha=\arcsin \left(\Delta_{x} / s\right)$ and the Platform's $y$-displacement can be found as $\Delta_{y}=s(1-$ $\cos \alpha$ ). The used cycloidal motion profile and the cost function are plotted in Fig. 6. As visible, $e_{\text {tra }}$ is monotonic over the design domain and its minimum is located at $s_{\max }$ (set equal to $180 \mathrm{~mm}$ ).

Despite its limited relevance from a design standpoint, the above described study allows to teach the combined use of the optimizer (PTC Creo Behavioural) and a CAE solver (PTC Creo Mechanism). To perform the optimization, the following tasks have to be completed in PTC Creo:

1. define the input motion for the Platform (Fig. 6a);

2. assign the programmed motion profile for the Platform, $\Delta_{x}=\Delta_{x}(t)$, to $C 1$ (or $C 2$ ), being $\alpha=\arcsin \left(\Delta_{x} / s\right.$ );

3. perform a kinematic simulation and evaluate the crank motion ( $\theta$ angle at $\mathrm{R} 1$ ) by means of a position measure (Fig. 6b);

4. set the measured profile, $\theta=\theta(t)$, as input rotational motion at $\mathrm{R} 1$ and remove the previous input motion;

5. assign the parameter to dimension $s$ in the CAD and make sure that all the geometrical features can correctly update whenever such parameter changes;

6. define the trajectory error evaluation through the MBD measure tool;

7. set the optimization problem (lower/upper bounds, number of iterations, tolerances, etc.);

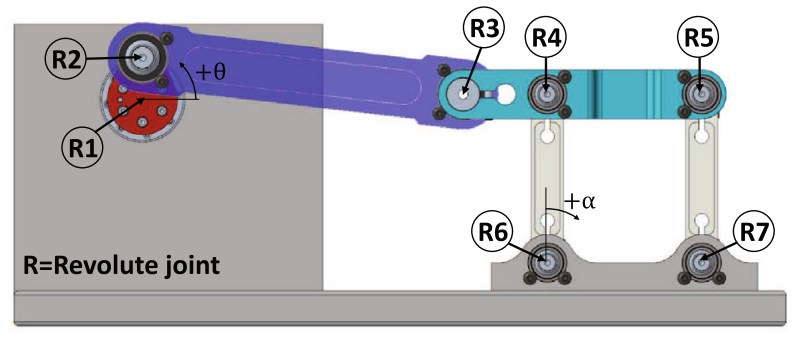

(a) APD overconstrained CAD model.

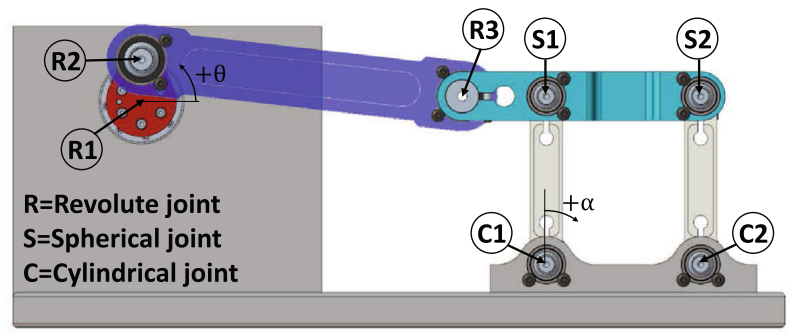

(b) APD correct CAD model.

Fig. 4 Critical revision of the applied joints

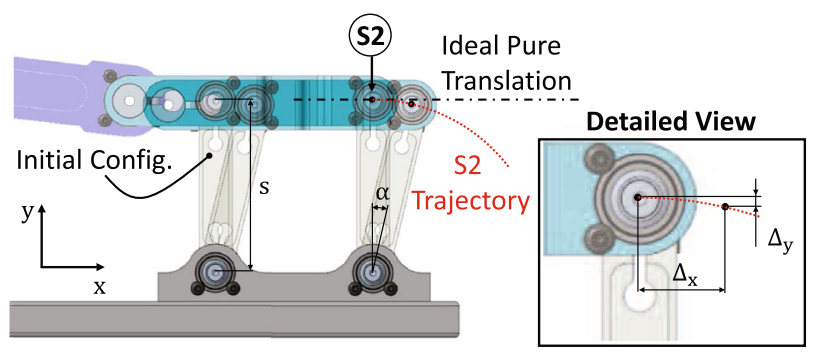

Fig. 5 Parametric model for kinematic optimization: comparison between ideal and real platform's trajectory

8. visualize the convergence plot and the final results (Fig. 6c);

9. review the results and update the CAD model.

At the end of this exercise, the students are more familiar with the parametric design and are ready to deal with more complicated steps.

\subsection{Step \#3: dynamic analysis and optimization}

After the Step \#2, the CAD model is updated and checked again. The new APD's CAD is visible in Fig. 7 (with $s=$ $180 \mathrm{~mm}$ ). The aim of Step \#3 is to compute the required actuation torque for a specific input motion. To be consistent with Step \#2, the cycloidal motion law shown in Fig. 6a is kept throughout the design process. Consequently, after assigning the mass properties to the APD's components (Aluminum alloy, with density equal to $\rho=2795 \mathrm{~kg} / \mathrm{m}^{3}$ ), the actuation torque can be obtained via a single dynamic simulation. The 

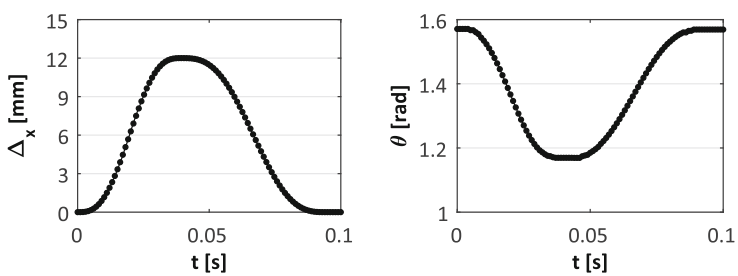

(a) Platform motion along (b) Related crank motion. $\mathrm{x}$-direction.

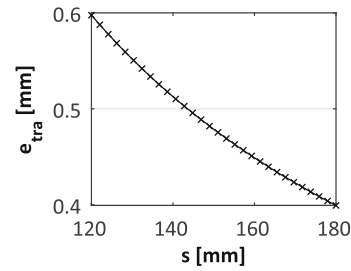

(c) Platform's trajectory error over the design domain.

Fig. 6 Imposed motion and optimization results

motion profile shown in Fig. $6 \mathrm{~b}$ is applied at R1, and the reaction torque is measured. The exercise is repeated with many cycle time (i.e. by scaling $\theta(t)$ on the time-axis) so as to observe the direct effect on the computed actuation torque.

Then, by fixing the APD's dimensions, an optimization is performed to find the most convenient actuator's location in the frame, that is the one that minimizes the actuation torque for the required motion. Similarly to the previous step, the problem is completed by leveraging the PTC Creo Behavioural optimizer, and can be formalized as follows:

$$
\text { minimize } \quad M_{r m s}=\sqrt{\frac{1}{n} \sum_{i=1}^{n} M_{i}^{2}}
$$

with respect to

$$
x_{0}
$$

subjected to $\quad x_{0, \min } \leq x_{0} \leq x_{0, \max }$

where $M_{r m s}$ represents the root mean square (rms) value of the actuation torque, evaluated for each candidate in a series of $n$ simulation steps, whereas $x_{0}$, assumed as design parameter, is the distance between R1 and R3 (see Fig. 7). Consequently, having set $\alpha=0$ as the initial position (the one for $t=0$ ) in the model, a variation in the value of $x_{0}$ would necessarily move the actuator's axis location in the frontal plane, as shown in Fig. 7. To ensure that the Platform performs the same displacement along the $x$-direction, $\Delta_{x}(t)$, at each iteration of the optimization process, the motion is applied at $\mathrm{C} 1$ instead of R1. The angular position law, $\alpha=\alpha(t)$, is reported in Fig. 8a.

The lower/upper bounds, $x_{0, \min }$ and $x_{0, \max }$, have to be determined based on the maximum position reached by the Platform during the motion, $\Delta_{x, \max }$. The maximum angle at $\mathrm{C} 1$ is then equal to $\alpha_{\max }=\arcsin \left(\Delta_{x, \max } / s\right)$ and, by fol-

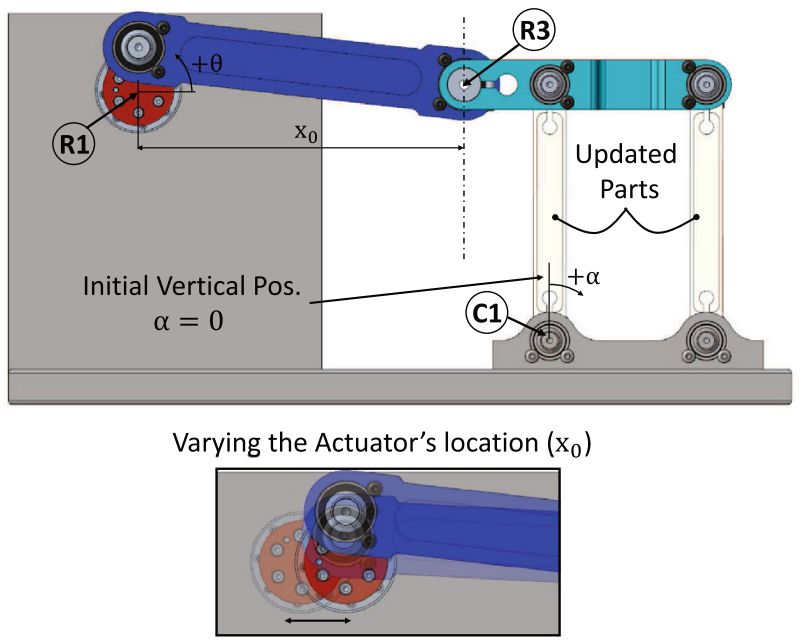

Fig. 7 Parametric model for dynamic optimization: influence of the actuator's location

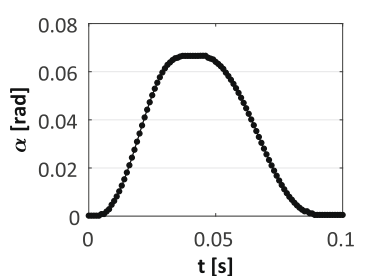

(a) Imposed motion at $\mathrm{C} 1$ $(s=180 \mathrm{~mm})$.

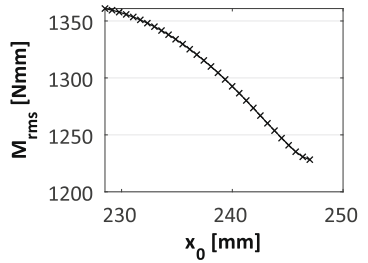

(b) Actuation torque (rms) over the design domain.
Fig. 8 Imposed motion at $\mathrm{C} 1$ and cost function

lowing simple trigonometric passages, it is possible to write:

$$
\begin{aligned}
& {\left[r \sin \theta-\left(e-s\left(1-\cos \alpha_{\max }\right)\right)\right]^{2}+} \\
& {\left[x_{0}+s \sin \alpha_{\max }-r \cos \theta\right]^{2}=l^{2}}
\end{aligned}
$$

from which the value of $x_{0, \min }$ and $x_{0, \max }$ can be easily evaluated. By ensuring that the inertia is the only dynamic contribute in the model, in other words by neglecting all the others (joints friction/damping, external disturbances, etc.) the actuation torque at the crank shaft, $\mathrm{M}$, can be evaluated at each simulation step by exploiting the power balancing principle. In practice, the reaction torque is to be measured at $\mathrm{C} 1$ as a direct effect of the applied motion $\alpha=\alpha(t)$, whereas the angular velocity is available for both $\mathrm{R} 1$ and $\mathrm{C} 1$ joints. The following relation is then set as "user-defined" measure in the MBD measure tool:

$M(t)=M_{R 1}(t)=\frac{M_{C 1}(t) \dot{\alpha}(t)}{\dot{\theta}(t)}$

and its rms value becomes the cost function in the optimization (see Eq. 4). As a result of varying $x_{0}$, the force transmission through linkages changes in the APD, producing different torques at the crank shaft. The sub-optimal 

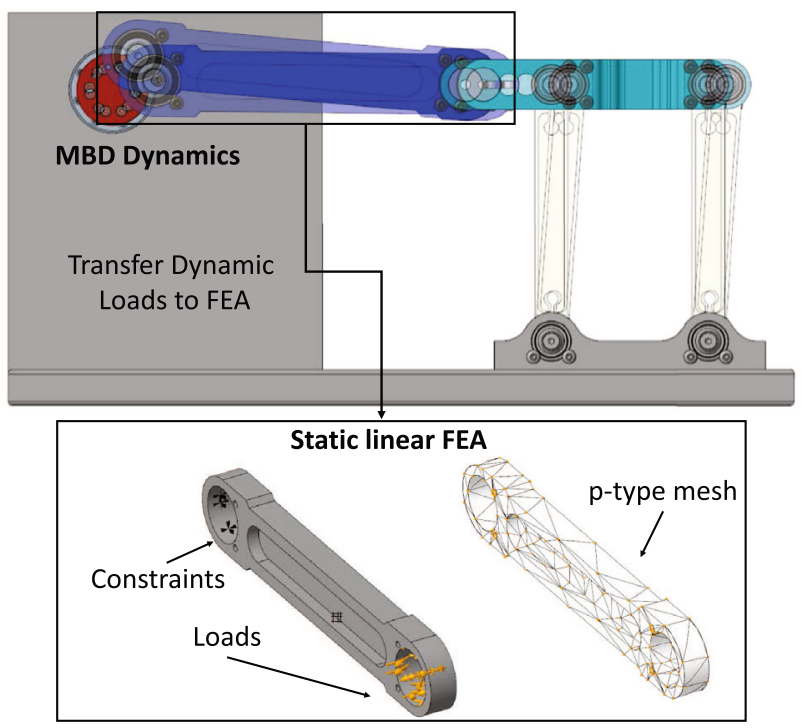

Fig. 9 Automatic load transfer from MBD to FEA

APD's configuration, shown in Fig. 7, is characterized by a pure vertical crank for $t=0$. As expected, the optimization tends to increase $x_{0}$ so as to reduce the torque at the crank shaft as the direct effect of varying the mechanical advantage in the linkage. The cost function is reported in Fig. $8 \mathrm{~b}$ and the minimum is found for $x_{0}=247 \mathrm{~mm}$. The CAD model is then updated accordingly.

\subsection{Step \#4: structural analysis and optimization}

The Step \#4 of the proposed design flow employs the integrated FEA solver (PTC Creo Simulate) for the structural analysis of one APD's component. As it can be noted from Fig. 9, among the APD's parts, the rod body is unquestionably over-sized for its task. To evaluate such excess of material, a first FEA simulation is performed on the component. Following the schematic reported in Fig. 9, the loads to be applied to the rod in the static FEA have been evaluated through a dynamic simulation in the MBD environment, with an input position law assigned at R1. Being the position law of Fig. 6b not valid when $x_{0}=247 \mathrm{~mm}$ (i.e. after the last model update), the phases 1 to 4 of the software procedure outlined in Sec. 3.2 have to be repeated to obtain the new motion profile for the crank. The new law generates the same output motion of the Platform, namely the one visible in Fig. 6a.

Once the dynamic simulation is completed, the worst load case scenario, namely the load-set containing the maximum value for each of the loads acting on the rod during the motion, is extracted during the post-processing and subsequently imported into the FEA environment. From a functional standpoint, this load-set may result too conservative as it comprises loads registered at different simulation steps. However, in the actual context, it copes well with the

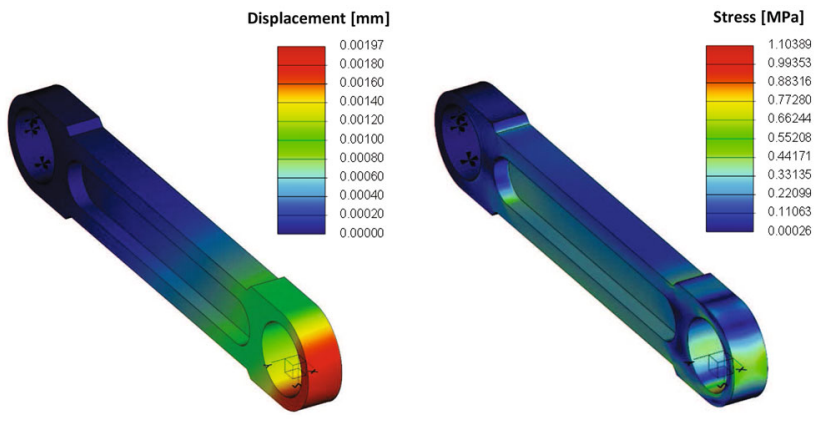

Fig. 10 FEA results on the initial sub-optimal rod component

need to evaluate the rod's safety factor, $S_{f}$, defined as the ratio between the material's elastic limit and the maximum occurred Von Mises stress in FEA. Concerning the material properties, the Young's modulus and the elastic limit are set respectively equal to $73000 \mathrm{MPa}$ and $400 \mathrm{MPa}$.

In the FEA environment, the rod is fixed from one extremity (the crank side) and is loaded at the other extremity with the imported loads. The selected boundary conditions aim to diversify the actuator's side, considered more rigid, from the platform's side, where the major inertia contributes are to be manifested. PTC Creo Simulate also allows to analyze linear problems with unconstrained models thanks to the "inertia relief" option. To remove the six DoFs, this option automatically defines a constraint set containing three-point constraints in the model. Also, the solver applies body loads that balance the external applied loads. Since the three-point constraints affect the displacement solution, this method seems not to be effective for students that approach the package for the first time. As for the meshing operations, the p-element method simplifies the element generation and does not require high expertise for completing the model. In fact, instead of constantly refining the meshes, the user can simply increase the order of the interpolating polynomials. For a detailed discussion about the p-element meshing method, the interested reader is referred to [52].

The results of the first static test, carried out on the suboptimal rod, are reported in Fig. 10. The limited registered stress (about $1 \mathrm{MPa}$, which gives $S_{f}=363$ ) confirms the excess of material and lays the foundation for the subsequent structural optimization [7]. The new problem is set as minimizing the rod's mass (or volume) while keeping the maximum displacement less than a threshold, i.e.:

$$
\text { minimize mass }
$$

with respect to $\quad b_{1}, b_{2}, t$

subjected to

$$
\begin{aligned}
& \left|\delta_{i}\right| \leq 0.01 \mathrm{mmi}=1, . ., m \\
& b_{1, \min } \leq b_{1} \leq b_{1, \text { max }} \\
& b_{2, \min } \leq b_{2} \leq b_{2, \max } \\
& t_{\text {min }} \leq t \leq t_{\max }
\end{aligned}
$$




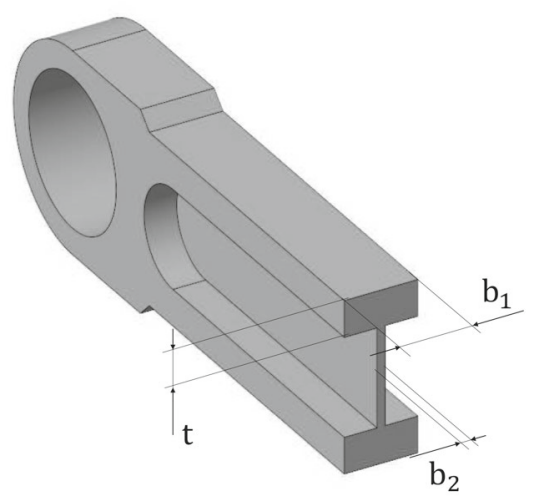

Fig. 11 Dimensional parameters for the structural optimization
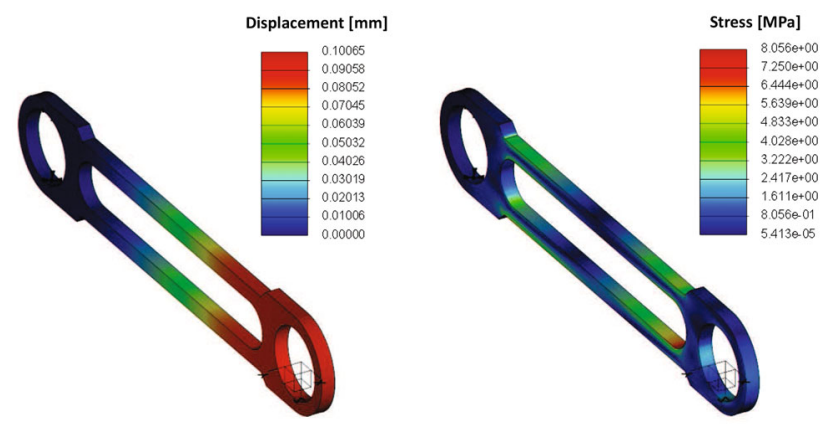

Fig. 12 FEA results on the optimal rod component

where $b_{1}, b_{2}$ and $t$ are the selected dimensional parameters, as in Fig. 11, whereas $\left|\delta_{i}\right|$ is the module of the nodal displacement registered at the $i$-th node, being $m$ the total number of nodes in the FEA model. The problem converged after a limited number of iterations (less than 50) and took approximately 1 hour to complete using a personal computer with an Intel(R) Core(TM) CPU @ $2.5 \mathrm{GHz}$ and $16 \mathrm{~GB}$ RAM. The optimal parameter set is $b_{1}=7 \mathrm{~mm}, b_{2}=0 \mathrm{~mm}$ and $t=7.75 \mathrm{~mm}$. The final rod, whose behavior is reported in Fig. 12, provides a mass reduction of $66.5 \%$ with respect of the initial sub-optimal configuration, i.e. from $322 \mathrm{~g}$ to $108 \mathrm{~g}$, with obvious benefits in terms of cost reduction and actuation effort. At last, the maximum nodal displacement is $0.1 \mathrm{~mm}$, whereas the maximum Von Mises stress arising in the component is $8 \mathrm{MPa}\left(S_{f}=50\right)$.

The rod's optimization is considered as mandatory for the PjBL activity. Then, as an optional assignment for the students, the above described procedure is to be applied to the rest of the APD's parts, starting from the Link 1,2 or the Platform.

\subsection{Step \#5: actuator selection}

The APD's CAD is updated to incorporate the optimized rod. Figure 13 shows the APD system and summarizes the changes made as a result of the optimizations carried out in

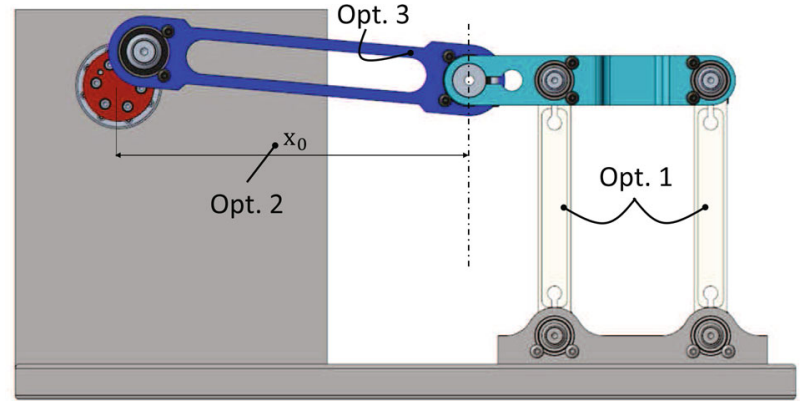

Fig. 13 Final APD CAD model

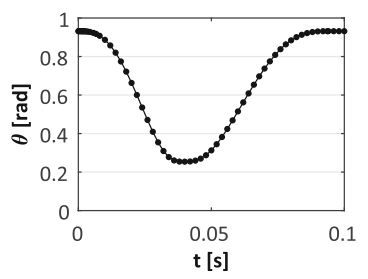

(a) Crank motion profile.

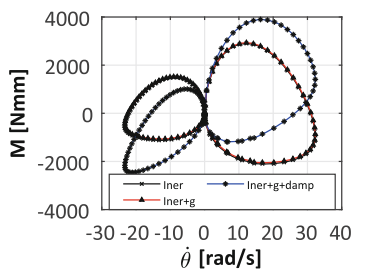

(b) Effect of inertia, gravity and damping on the APD's torque-speed curve.
Fig. 14 Actuator selection: MBD simulation results

the previous sections. To conclude the CAD/CAE project, a commercial brushless electric motor is selected for actuating the APD. The selection is quite straightforward for mechanical systems that operate in static conditions, i.e. with almost null transients, such as an electric motor pulley for lifting. On the contrary, when dealing with high-dynamic loads, the power supplied by the motor depends on the external load applied, but also on the inertia acting on the system and on other dynamic forces (e.g. damping in the parts/joints or transmission). Many procedures are available for this important step (a practical guide can also be found in [53]). The method reported hereinafter allows to perform the task within the CAD/CAE environment [54], though a calculation tool (e.g. Excel) for comparing the MBD results with the commercial available motors' characteristics is helpful.

The selection is bound by the limitations imposed by the motor's working range, and the choice of a specific motion law is the first parameter to be defined when sizing the motor, because it allows to extrapolate the load characteristics. To be consistent with the previous steps, the same cycloidal position law is considered in Step \#5. A new set of three dynamic simulations has been carried out in PTC Creo Mechanism with an input rotational law at R1 (shown Fig. 14a) so as to obtain the APD's torque-speed curve in the following conditions:

1. in presence of inertia;

2. in presence of inertia and gravity; 


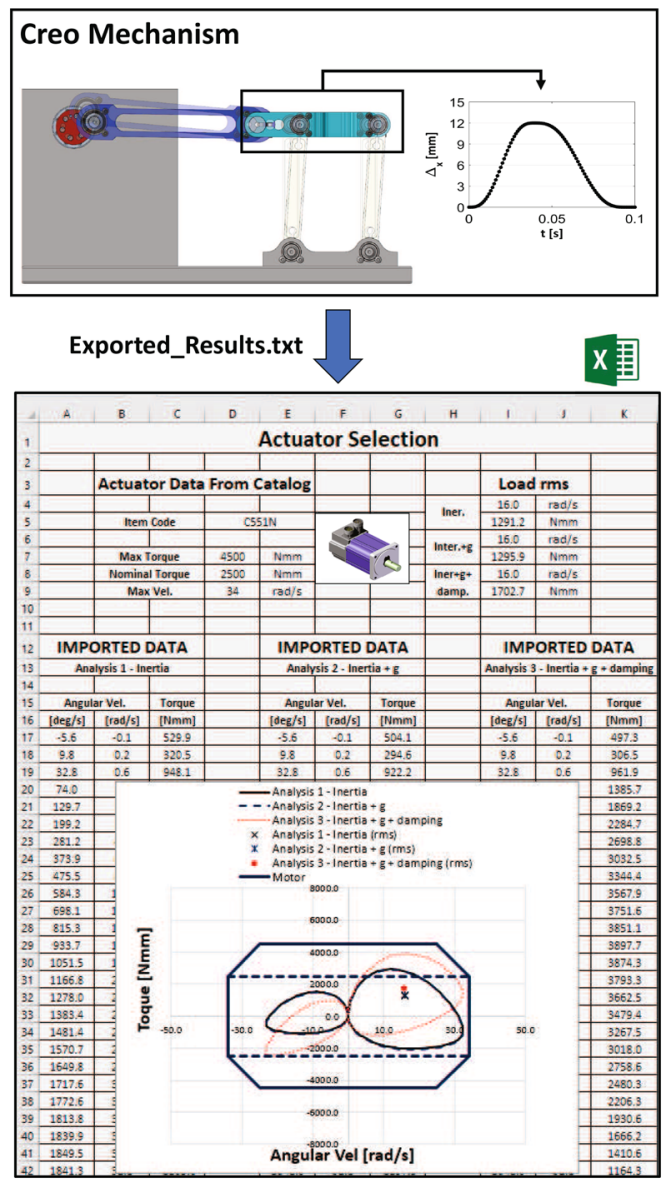

Fig. 15 Actuator selection flowchart

3. in presence of inertia, gravity and damping in the APD's joints.

The numerical results, namely $\dot{\theta}$ and $M$, are processed via the MBD measure tool (see Fig. 14b) and then exported from PTC Creo and imported in Excel for direct comparison with the motors' curve obtained from the manufacturer's catalogs, as shown in Fig. 15. The curves are overlapped as in Fig. 15, and the motor's limit are checked. The proper actuator selection is based on the following principles:

- The load curve must lie within the motor's working area, namely the so-called actuator characteristic curve, whereas the rms value of the load curve must lie into the motor's continuous working area, i.e. the central one delimited by dotted lines in Fig. 15. Methods for optimal selection of the motor reducer are discussed in [53], and they are briefly recalled during the theory classes.

- Economically speaking, the motor's cost increases with the motor's dimensions. Consequently, it is mostly advisable to select smaller motors rather than over-sizing the actuation system.
Therefore, the task can be completed by selecting the cheapest available motor that fits the functional requirements. Naturally, in case of multiple motion laws or cycle times, the procedure needs to be repeated to ensure that the new conditions match with the chosen actuator.

At this point, the CAD/CAE process is checked and the final report is produced. The document summarizes the main methods and results, but it also includes a section for critical reviews and discussions about possible design improvements (e.g. new conceptual solutions [55], alternative mechanism topologies [56,57], further optimize motion laws to reduce tracking errors or energy consumption $[58,59]$, etc.).

\section{Survey results}

From the lecturers' point of view, in line with [60], the main factors that determine the effectiveness of the PjBL in mechanical engineering curricula are:

1. the level of interest shown by the students, strongly stimulated by the initial industrial seminar, which shows the real attention of the companies for both the activity and the modern integrated CAD/CAE technologies;

2. the students' background in the most important disciplines of mechanical engineering (e.g. Technical Drawing and 3D CAD Modeling, Machine Design, Mechanics of Machines, etc.);

3. the project to be developed, which has to be configured by taking into account the groups' size, the students' level of expertise, and the total amount of time available for the PjBL activity.

As observed in the four years experience, dealing with simple theoretical concepts definitely improves the students' understanding of the parametric $\mathrm{CAD} / \mathrm{CAE}$ tools and ensures the correct balancing between command knowledge and strategic knowledge. Following this approach, most of the class time is spent trying to solve the sequential engineering problem through the integrated $\mathrm{CAD} / \mathrm{CAE}$ tool rather than recalling complex theories. Also, there are advantages when using industrial related case studies in $\mathrm{PjBL}$, since they ensure high participation and interest from the students that, for the first time in their career, play an active role and face problems with an industrial perspective. Overall, the implementation of the PjBL has been particularly satisfactory for the lecturers. As an optional subject of the last year program, the most challenging aspect for the lecturers is the non-uniform student's CAD knowledge.

At the end of the semester, the students' opinions about the $\mathrm{PjBL}$ activity are collected with anonymous questionnaires. In particular, the activity rating is summarized by three main points: 


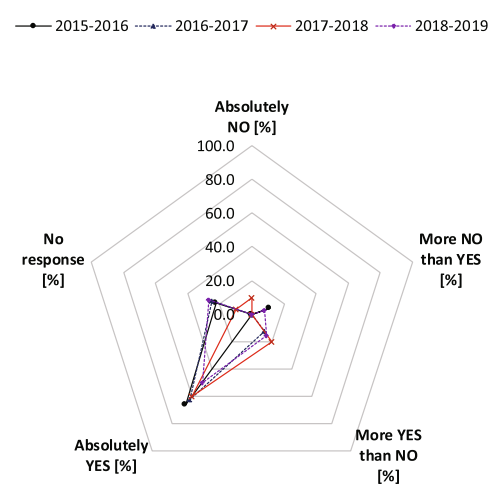

(a) PjBL's efficacy for didactical purpose.
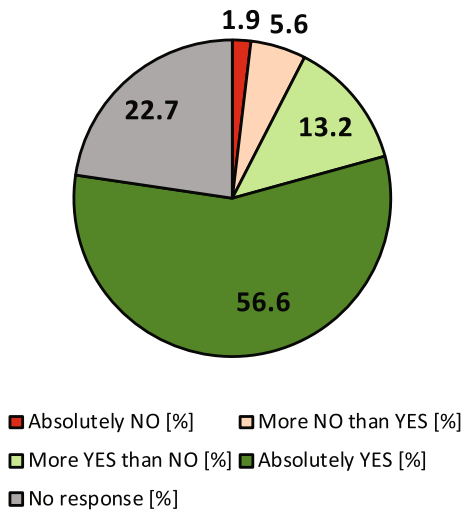
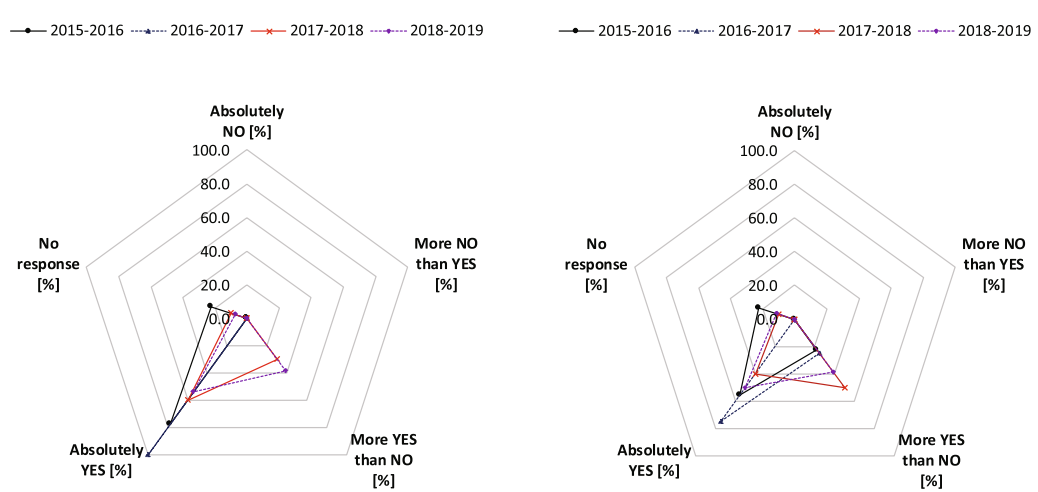

(b) Quality of teaching and acquired (c) Consistency with theoretical backskills.
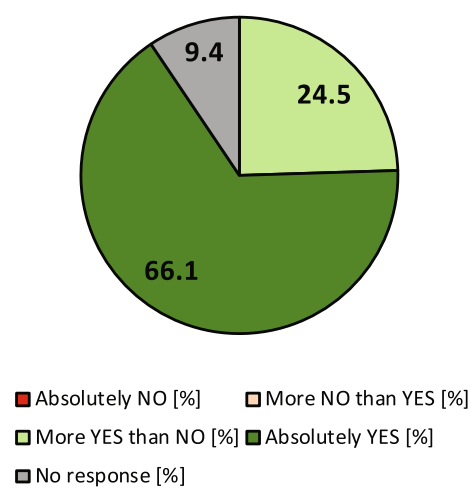

ground.
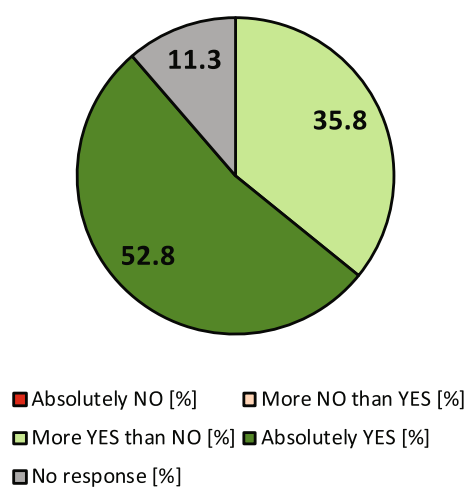

(d) Weighted average of results in (a) (e) Weighted average of results in (b) (f) Weighted average of results in (c) based on the number of students per based on the number of students per based on the number of students per year. year. year.

Fig. 16 Students' opinions about the PjBL activity in the last four academic years. Detailed statistics are reported in a-c, whereas weighted average results are summarized in $\mathbf{d}-\mathbf{f}$

- PjBL's efficacy for didactic purpose;

- quality of teaching and acquired skills;

- consistency with theoretical background.

For each item the possible scores are: (i) No response, (ii) Absolutely NO, (iii) More NO than YES, (iv) More YES than NO, and (v) Absolutely YES. The results from the last four years are reported in Fig. 16. The statistics refers to a number of students equal, respectively, to 10 for the academic year 2015-2016, to 16 for the academic year 2016-2017, to 14 for the academic year 2017-2018 and to 28 for the academic year 2018-2019. The year over year trends are plotted in Fig. 16a$c$, whereas the weighted averages based on the number of students per year are diagrammed in Fig. 16d-f. The overall positive trend of the collected feedbacks ( $\geq 69.1 \%$ for each category) strongly stimulates the lecturers to continue this kind of didactic approach.

\section{Conclusions}

This paper has discussed about the PjBL activity implemented during the last years at the University of Genova within the course named Design of Automatic Machines. The intent of the PjBL activity is, on one hand, to show to future engineers the use of an integrated CAD/CAE design tool and, on the other hand, to stimulate the students' ability in solving real problems and to interactively work in a group. Every year, a professional engineer from industry presents a new case study taken from a commercial automatic machine. The students are then asked to go through a sequential design process that aims at solving, step-by-step, a series of issues raised up by the engineer. All the design steps, namely the CAD assembly, the trajectory optimization, the search of the most convenient actuator's position, the structural optimization of components and the actuator selection, are processed 
using a single CAD/CAE integrated package (i.e. PTC Creo). Detailed explanations of the adopted software procedures are given throughout the paper, which also summarizes the main numerical results. The last part of the paper reports the lecturers' perspective and the students' point of view about the PjBL activity. Based on the collected feedback, it seems that $\mathrm{PjBL}$ is likely to be an effective strategy to introduce to the students the design methods and tools to be utilized in their future working careers. To keep consistency with the actual industrial trends, future work will possibly integrate the topology optimization and the 3D printing technologies into the PjBL approach.

Acknowledgements Open access funding provided by Università degli Studi di Genova within the CRUI-CARE Agreement.

Funding The research has received funding from University of Genova grant - COSMET, COmpliant Shell-based mechanisms for MEdical Technologies and from Interreg Grant AMiCE - Advanced Manufacturing in Central Europe.

Open Access This article is licensed under a Creative Commons Attribution 4.0 International License, which permits use, sharing, adaptation, distribution and reproduction in any medium or format, as long as you give appropriate credit to the original author(s) and the source, provide a link to the Creative Commons licence, and indicate if changes were made. The images or other third party material in this article are included in the article's Creative Commons licence, unless indicated otherwise in a credit line to the material. If material is not included in the article's Creative Commons licence and your intended use is not permitted by statutory regulation or exceeds the permitted use, you will need to obtain permission directly from the copyright holder. To view a copy of this licence, visit http://creativecomm ons.org/licenses/by/4.0/.

\section{References}

1. Gu, N., Wan, X.: Computational design methods and technologies: applications in CAD, CAM, and CAE education. Information Science Reference, (2012)

2. Um, D.: Solid Modeling and Applications. Springer, Berlin (2015)

3. Design Theory and Methods Using CAD/CAE: The Computer Aided Engineering Design Series. Academic Press, Cambridge (2014)

4. Hadj, R.B., Belhadj, I., Gouta, C., Trigui, M., Aifaoui, N., Hammadi, M.: An interoperability process between cad system and cae applications based on cad data. Int. J. Interact. Des. Manuf. 12(3), 1039-1058 (2018)

5. Pan, Z., Wang, X., Teng, R., Cao, X.: Computer-aided designwhile-engineering technology in top-down modeling of mechanical product. Comput. Ind. 75, 151-161 (2016)

6. Bilancia, P., Berselli, G., Bruzzone, L., Fanghella, P.: A CAD/CAE integration framework for analyzing and designing spatial compliant mechanisms via pseudo-rigid-body methods. Robot. Comput. Integr. Manuf. 56, 287-302 (2019)

7. Park, H.-S., Dang, X.-P.: Structural optimization based on CADCAE integration and metamodeling techniques. Comput. Aided Des. 42(10), 889-902 (2010)

8. Tornincasa, S., Bonisoli, E., Di Monaco, F.: Virtual prototyping through multisoftware integration for energy harvester design. J. Intell. Mater. Syst. Struct. 25(14), 1705-1714 (2014)
9. Wang, J., Niu, W., Ma, Y., Xue, L., Cun, H., Nie, Y., Zhang, D.: A CAD/CAE-integrated structural design framework for machine tools. Int. J. Adv. Manuf. Technol. 91(1-4), 545-568 (2017)

10. Bilancia, P., Berselli, G., Bruzzone, L., Fanghella, P.: A practical method for determining the pseudo-rigid-body parameters of spatial compliant mechanisms via CAE tools. Proc. Manuf. 11, 1709-1717 (2017)

11. Soe, S.P., Martindale, N., Constantinou, C., Robinson, M.: Mechanical characterisation of duraform ${ }^{\circledR}$ flex for FEA hyperelastic material modelling. Polym. Testing 34, 103-112 (2014)

12. Vilau, C., Balc, N., Leordean, D., Cosma, C.: Static analysis to redesign the gripper, using creo parametric software tools. Acad. J. Manuf. Eng. 13(1), 77 (2015)

13. Jin, M., Zhang, X.: A new topology optimization method for planar compliant parallel mechanisms. Mech. Mach. Theory 95, 42-58 (2016)

14. Morales-Avalos, J.R., Heredia-Escorza, Y.: The academia-industry relationship: igniting innovation in engineering schools. Int. J. Interact. Des. Manuf. 13(4), 1297-1312 (2019)

15. Hernandez-de Menendez, M., Díaz, C.E., Morales-Menendez, R.: Technologies for the future of learning: state of the art, pp. 113. International Journal on Interactive Design and Manufacturing (IJIDeM), (2019)

16. Dimitrov, L.: A CAD software package for education in the discipline of machine element design. Eur. J. Eng. Educ. 18(3), 285-291 (1993)

17. Hernandez-de Menendez, M., Morales-Menendez, R.: Technological innovations and practices in engineering education: a review. Int. J. Interact. Des. Manuf. 13(2), 713-728 (2019)

18. Ye, X., Peng, W., Chen, Z., Cai, Y.-Y.: Today's students, tomorrow's engineers: an industrial perspective on CAD education. Comput. Aided Des. 36(14), 1451-1460 (2004)

19. Gobin, R.: Computer aided design in engineering education. Eur. J. Eng. Educ. 11(2), 127-134 (1986)

20. Bhavnani, S.K., Reif, F., John, B.E.: "Beyond command knowledge: Identifying and teaching strategic knowledge for using complex computer applications". In Proceedings of the SIGCHI conference on Human factors in computing systems, pp. 229-236, (2001)

21. Barbero, B.R., Pedrosa, C.M., Samperio, R.Z.: Learning CAD at university through summaries of the rules of design intent. Int. J. Technol. Des. Educ. 27(3), 481-498 (2017)

22. Chester, I.: Teaching for CAD expertise. Int. J. Technol. Des. Educ. 17(1), 23-35 (2007)

23. Fanghella, P., Berselli, G., and Bruzzone, L.: "Analytical or computer-aided graphical methods for introductory teaching of mechanism kinematics?". In New Trends in Educational Activity in the Field of Mechanism and Machine Theory. pp. 149-156. Springer, Berlin (2019)

24. Ravikumar, P., McDonald, B., Shin, I.-S., Zbeeb, K., Puneeth, N.: "Enhancing learning of kinematics and fatigue failure theories using CAD modeler". In Advances in Engineering Design. pp. 289-300, Springer, Berlin (2019)

25. Wiggins, E .G.: Using CAD to help students learn statics. ASEE Comput. Educ. J. 5(3), 72 (2014)

26. Jaakma, K., Kiviluoma, P.: Auto-assessment tools for mechanical computer aided design education. Heliyon 5(10), e02622 (2019)

27. Kirkwood, R., Sherwood, J.A.: Sustained CAD/CAE integration: integrating with successive versions of step or iges files. Eng. Comput. 34(1), 1-13 (2018)

28. Barbero, B.R., García García, R.: Strategic learning of simulation and functional analysis in the design and assembly of mechanisms with CAD on a professional master's degree course. Comput. Appl. Eng. Educ. 19(1), 146-160 (2011)

29. Díaz Lantada, A., Lafont Morgado, P., Munoz-Guijosa, J.M., Echávarri Otero, J., Muñoz Sanz, J.L.: Comparative study of CAD-CAE 
programs taking account of the opinions of students and teachers. Comput. Appl. Eng. Educ. 21(4), 641-656 (2013)

30. García, R.R., Quirós, J.S., Santos, R.G., Peñín, P.I.Á.: Teaching $\mathrm{CAD}$ at the university: specifically written or commercial software? Comput. Educ. 49(3), 763-780 (2007)

31. Seah, Y.Y., Magana, A.J.: Exploring students experimentation strategies in engineering design using an educational CAD tool. J. Sci. Educ. Technol. 28(3), 195-208 (2019)

32. Di Angelo, L., Leali, F., Di Stefano, P.: Can open-source 3D mechanical CAD systems effectively support university courses. Int. J. Eng. Educ 32(3), 1313-1324 (2016)

33. Mills, J.E., Treagust, D.F., et al.: Engineering education-is problem-based or project-based learning the answer. Aust. J. Eng. Educ. 3(2), 2-16 (2003)

34. Prince, M.J., Felder, R.M.: Inductive teaching and learning methods: definitions, comparisons, and research bases. J. Eng. Educ. 95(2), 123-138 (2006)

35. Chen, C.-H., Yang, Y.-C.: Revisiting the effects of project-based learning on students academic achievement: a meta-analysis investigating moderators. Educ. Res. Rev. 26, 71-81 (2019)

36. Hernández-de Menéndez, M., Guevara, A.V., Martínez, J.C.T., Alcántara, D.H., Morales-Menendez, R.: Active learning in engineering education. a review of fundamentals, best practices and experiences. Int. J. Interact. Des. Manuf. 13(3), 909-922 (2019)

37. Freeman, S., Eddy, S.L., McDonough, M., Smith, M.K., Okoroafor, N., Jordt, H., Wenderoth, M.P.: Active learning increases student performance in science, engineering, and mathematics. Proc. Nat. Acad. Sci. 111(23), 8410-8415 (2014)

38. Hall, W., Palmer, S., Bennett, M.: A longitudinal evaluation of a project-based learning initiative in an engineering undergraduate programme. Eur. J. Eng. Educ. 37(2), 155-165 (2012)

39. Martinez, M. L., Romero, G., Marquez, J. J., and Perez, J. M.: "Integrating teams in multidisciplinary project based learning in mechanical engineering". In IEEE EDUCON 2010 Conference, IEEE, pp. 709-715 (2010)

40. Moliner, L., Cabedo, L., Royo, M., Gámez-Pérez, J., LopezCrespo, P., Segarra, M., Guraya, T.: On the perceptions of students and professors in the implementation of an inter-university engineering PBL experience. Eur. J. Eng. Educ. 44(5), 726-744 (2019)

41. Abellán-Nebot, J.V.: Project-based experience through real manufacturing activities in mechanical engineering. Int. J. Mech. Eng. Educ. 48(1), 55-78 (2020)

42. Farrell, F., Carr, M.: The effect of using a project based learning (PBL) approach to improve engineering students understanding of statistics. Teach. Math. Appl. Int. J. IMA 38(3), 135-145 (2019)

43. Yahya, S., Moghavvemi, M., Almurib, H.A., Al-Rizzo, H.: A labview module to promote undergraduate research in control of AC servo motors of robotics manipulator. Comput. Appl. Eng. Educ. 28(1), 139-153 (2020)

44. Lipinski, K., Docquier, N., Samin, J.-C., Fisette, P.: Mechanical engineering education via projects in multibody dynamics. Comput. Appl. Eng. Educ. 20(3), 529-539 (2012)

45. Gil, P.: Short project-based learning with MATLAB applications to support the learning of video-image processing. J. Sci. Educ. Technol. 26(5), 508-518 (2017)

46. Lantada, A.D., Morgado, P.L., Muñoz-Guijosa, J.M., Sanz, J.L.M., Varri Otero, J., García, J.M., Tanarro, E.C., De La Guerra Ochoa, E.: Towards successful project-based teaching-learning experiences in engineering education. Int. J. Eng. Educ. 29(2), 476-490 (2013)
47. Lantada, A.D., Morgado, P.L., Munoz-Guijosa, J.M., Sanz, J., Otero, J.E., Garcia, J., Tanarro, E., Ochoa, E.: Study of collaboration activities between academia and industry for improving the teaching-learning process. Int. J. Eng. Educ. 29(5), 1059-67 (2013)

48. Lorenzo-Yustos, H., Lafont, P., Diaz Lantada, A., Navidad, A.F.F., Munoz Sanz, J.L., Munoz-Guijosa, J.M., Muñoz-Garcia, J., Echavarri Otero, J.: Towards complete product development teaching employing combined CAD-CAM-CAE technologies. Comput. Appl. Eng. Educ. 18(4), 661-668 (2010)

49. Barrows, H .S., Tamblyn, R .M., et al.: Problem-Based Learning: An Approach to Medical Education. Springer, Berlin (1980)

50. Garikano, X., Garmendia, M., Manso, A.P., Solaberrieta, E.: Strategic knowledge-based approach for CAD modelling learning. Int. J. Technol. Des. Educ. 29(4), 947-959 (2019)

51. Robertson, B .F., Walther, J., Radcliffe, D .F.: Creativity and the use of CAD tools: lessons for engineering design education from industry. J. Mech. Des. 129(7), 753-760 (2007). 01

52. Toogood, R.: Creo Simulate 6.0 Tutorial Structure/Thermal. SDC Publications, (2019)

53. Giberti, H., Cinquemani, S., Legnani, G.: A practical approach to the selection of the motor-reducer unit in electric drive systems. Mech. Based Des. Struct. Mach. 39(3), 303-319 (2011)

54. Berselli, G., Balugani, F., Pellicciari, M., Gadaleta, M.: Energyoptimal motions for servo-systems: a comparison of spline interpolants and performance indexes using a cad-based approach. Robot. Comput. Integr. Manuf. 40, 55-65 (2016)

55. Renzi, C., Leali, F., Pellicciari, M., Andrisano, A.O., Berselli, G.: Selecting alternatives in the conceptual design phase: an application of Fuzzy-AHP and Pugh's Controlled Convergence. Int. J. Interact. Des. Manuf. 9(1), 1-17 (2013)

56. Wang, H., Yu, W., Chen, G.: An approach of topology optimization of multi-rigid-body mechanism. Comput. Aided Des. 84, 39-55 (2017)

57. Norton, R.L.: Design of Machinery: An Introduction to the Synthesis and Analysis of Mechanisms and Machine. McGraw-Hill Higher Education, New York (2004)

58. Pellicciari, M., Berselli, G., Balugani, F.: On designing optimal trajectories for servo-actuated mechanisms: detailed virtual prototyping and experimental evaluation. IEEE/ASME Trans. Mechatron. 20(5), 2039-2052 (2015)

59. Meike, D., Pellicciari, M., Berselli, G., Vergnano, A., and Ribickis, L.: "Increasing the energy efficiency of multi-robot production lines in the automotive industry". In 2012 IEEE International Conference on Automation Science and Engineering (CASE), pp. 700-705 (2012)

60. Vassura, G., Macchelli, A.: Multi-disciplinary tutoring for projectbased mechatronics learning. IFAC Proc. Vol. 41(2), 15577-15582 (2008)

Publisher's Note Springer Nature remains neutral with regard to jurisdictional claims in published maps and institutional affiliations. 